\title{
EKSTRAKSI ION KROM DALAM ASAM NITRAT DENGAN TEKNOLOGI MEMBRAN CAIR UNTUK LIMBAH INDUSTRI PENYAMAKAN KULIT
}

\author{
Dwi Wahini Nurhajati ${ }^{1)}$, Prayitno $^{2)}$, Endro Kismolo ${ }^{2)}$
}

\begin{abstract}
INTISARI
Penelitian ini bertujuan untuk meneliti teknik membran cair dalam ekstraksi krom pada larutan asam nitrat. Fasa membran yang berupa emulsi terdiri dari kerosen sebagai pelarut, sorbitan monooleat (span-80) sebagai surfaktan, tri oktil amin (TOA), sebagai zat pembawa serta natrium hidroksida sebagai fasa internal. Kondisi optimum yang diperoleh untuk pembuatan membran cair, fasa membran terdiri dari fasa organik (O), fasa air inter$\mathrm{nal}(\mathrm{W})$ dengan perbandingan $\mathrm{O} / \mathrm{W}=1$, konsentrasi sorbitan monooleat dalam fasa membran $4 \%(\mathrm{v} / \mathrm{v})$, waktu optimum pembuatan emulsi 4 menit, kecepatan pengadukan $8000 \mathrm{rpm}$. Kondisi optimum yang diperoleh untuk mengekstraksi krom dari larutan yang mengandung krom nitrat dengan prosen ekstraksi membran-cair sebesar $97,80 \%$ dan prosen ekstraksi cair-cair sebesar $81,24 \%$ adalah sebagai berikut : konsentrasi asam nitrat dalam fasa eksternal adalah $3 \mathrm{M}$, konsentrasi tri oktil amin dalam fasa membran adalah $5 \%(\mathrm{v} / \mathrm{v})$, konsentrasi natrium hidroksida, dalam fasa internal $1 \%(\mathrm{v} / \mathrm{v}), 1 \mathrm{M}$ dan lamanya waktu ekstraksi ialah 15 menit dan perbandingan volume fasa membran dan volume fasa eksternal adalah $1: 3$. Penambahan ion ferro dan seng dalam larutan krom akan menurunkan prosen ekstraksi krom.
\end{abstract}

\section{ABSTRACT}

The objective of the research was to use of liquid membrane emulsion technique for the extraction of chrom in the nitrate acid solution. The liquid membrane phase as emulsion consists of kerosene as the solvent, sorbitan monooleat (span-80) as the surfactant, trioktil amin , as the carrier, natrium hidroksida as the internal phase. The optimum conditions obtained for making membrane, the liquid membrane phase was consists of organic phase $(\mathrm{O})$, the internal liquid phase (W) with the ratio of $\mathrm{O} / \mathrm{W}=1$, the concentration sorbitan monooleat (span-80) in the membrane phase was $4 \%(v / v)$, the optimum time to achieve a emulsion was 5 minutes, the rate of stirring for membrane $8000 \mathrm{rpm}$. The optimum conditions obtained for extraction chrom ion as of chrom nitrate from solution with percentage of liquid membrane extraction used of $97,8 \%$ and the percentage of liquid-liquid extraction of $81,24 \%$ were as follow : the concentration of nitric acid in external phase was $3 \mathrm{M}$, the concentration of tri oktil amin in the membrane phase was $5 \%(\mathrm{v} / \mathrm{v})$, the concentration of natrium hidroksida in internal phase was $1 \%(\mathrm{v} / \mathrm{v})$, the extraction time was 15 minutes and volume ratio of membrane phase and external phase was $1: 3$. The addition of $\mathrm{Fe}$ and $\mathrm{Zn}$ ions solution decreased the percent extraction of chrom ion.

1) Balai Besar Penelitian dan Pengembangan Industri Barang Kulit, Karet dan Plastik, Yogyakarta.

2) Puslitbang Teknologi Maju BATAN

Majalah Barang Kulit, Karet dan Plastik, Vol. XV, No. 2, Tahun 1999 


\section{PENDAHULUAN}

Membran cair merupakan fasa yang memisahkan fasa yang terbungkus dalam emulsi (fasa internal) dan fasa kontinyu (fasa eksternal). Fasa kontinyu ini berisi senyawa-senyawa yang akan dipisahkan, sedangkan fasa internal merupakan penampung bagi senyawa-senyawa yang terekstraksi. Fasa membran umumnya berisikan surfaktan, aditif dan pelarut bagi komponen lainnya. Surfaktan dan aditif digunakan untuk mengatur kestabilan, dan permeabilitas dari membran. Penggunaan membran cair telah dipublikasikan oleh N.N.Li pada tahun 1971. Pada tahun yang sama N.N.Li menerapkan peristiwa permeasi yang terjadi melalui membran cair bersurfaktan. Sejak itu, telah disebar luaskan hasil-hasil penelitian yang mengungkapkan aspek teoritis dan penerapan membran cair untuk pemisahan dan penurunan logam-logam berat dalam limbah.

Proses ekstraksi dengan membran cair merupakan penggabungan proses ekstraksi dan stripping dalam satu tahapan proses (Abou-Nemeh and Van Pethegem, 1993), sehingga pemisahan lebih cepat, efisiensi dari segi waktu dapat ditingkatkan, serta penggunaan ekstraktan lebih sedikit (Hayworth, 1993).

Proses pemisahan dengan emulsi membran cair tidak akan berhasil baik bila emulsi yang dibuat mengalami pemecahan, creaming, atupun flokulasi. Untuk mencegah itu, maka ke dalam emulsi tersebut biasanya ditambahkan suatu zat pengemulsi (surfaktan), yang mampu menurunkan tegangan permukaan antara fasa emulsi dengan fasa kontinu dan dapat membentuk film antara kedua fasa tersebut. Salah satu jenis surfaktan yang banyak dipakai dalam pembuatan emulsi adalah sorbitan monooleat atau SPAN-80 yang mempunyai dua gugus terpisah yaitu gugus alkil yang bersifat non polar dan gugus hidroksi yang bersifat polar. Sifatnya lebih larut dalam pelarut non polar, dengan harga Hydrophile-Lipophile Balance (HLB) 4.3, oleh sebab itu digunakan untuk menstabilkan emulsi tipe w/o (Abou-Nemeh 1993, Anief 1985 dan Johanes 1973). Emulsi yang kestabilannya tinggi tahan terhadap osmosis oleh air sehingga volume air dalam sistem akan relatif tetap tetapi ada kemungkinan perubahan volume fasa air internal. Perubahan volume $(\Delta \mathrm{V})$ positip yaitu fasa air eksternal masuk ke fasa air internal, sedangkan perubahan volume $(\Delta \mathrm{V})$ negatip yaitu fasa air internal keluar ke fasa air internal. Jika t adalah perubahan volume fasa air internal $(\Delta \mathrm{Vi})$ dibagi volume fasa air internal mula-mula (Vi) yaitu $: \tau=\left|\Delta V / \Delta V^{\circ}\right|$, maka kestabilan membran cair dapat dilihat dari nilai $\tau$. Semakin kecil harga $\tau$ maka membran semakin stabil. Di dalam membran, kompleks assosiasi ion ini berdifusi dari permukaan luar kepermukaan dalam membran. Pada permukaan dalam membran ini kompleks anion $\left[\mathrm{NO}_{3}\right]^{2-}$ dilepaskan ke dalam fasa internal yang mengandung air bebas ion. Reaksi yang terjadi pada permukaan bagian dalam membran adalah reaksi pelepasan kompleks anion $\left[\mathrm{Cr}_{2} \mathrm{O}_{7} \mathrm{NO}_{3}\right]$ dari kompleks asosiasi ion Selanjutnya kompleks anion $\left[\mathrm{Cr}_{2} \mathrm{O}_{7} \mathrm{NO}_{3}\right]^{-}$di fasa internal yang berisi air bebas ion terurai menjadi ion $\mathrm{Cr}_{2} \mathrm{O}_{7}{ }^{2-}$ dan ion $\mathrm{NO}_{3}$.

Menurut Frankenfeld (1981), proses transport ion logam ke dalam membran cair terjadi karena adanya gradien consentras" ion logam antara fasa internal dengan eksternal. Banyaknya ion logam-logam yang berdifusi ke dalam membran cair dinyatakan dengan persamaan :

\begin{tabular}{cc}
$\mathrm{dN}$ \\
\hdashline $\mathrm{d} \theta$
\end{tabular}


Keterangan :

$\mathrm{dN} / \mathrm{d} \theta$ = banyaknya materi yang berdifusi ke dalam membran per satuan waktu.

$\mathrm{D} \quad=$ koefisien difusi, $\mathrm{A}=$ luas antar muka

$\Delta \mathrm{C} \quad=$ perbedaan konsentrasi materi dalam fasa internal dengan fasa eksternal.

$\Delta \mathrm{X}=$ ketebalan membran

Karena luas antar muka (A) dan ketebalan membran (X) sukar ditentukan untuk sistem membran cair, maka harga D.A/ $\Delta \mathrm{X}$ pada persamaan (1) dapat diganti dengan $\mathrm{D}^{\prime}\left[\mathrm{V}_{\mathrm{M}} / \mathrm{V}_{\mathrm{E}}\right]$ sehingga persamaan (1) menjadi :

$$
\mathrm{dN} / \mathrm{d} \theta=\mathrm{D}^{\prime}\left[\mathrm{V}_{\mathrm{M}} / \mathrm{V}_{\mathrm{E}}\right]
$$

$\mathrm{D}^{\prime} \quad=$ koefisien difusi (kecepatan penembusan) yang efektif

$\mathrm{V}_{\mathrm{M}} / \mathrm{V}_{\mathrm{E}}=$ perbandingan volume fasa membran (emulsi) dengan volume fasa eksternal

Bila persamaan (2) disederhanakan maka diperoleh persamaan (3) sebagai berikut :

$$
\mathrm{D}^{\prime}=\ln \mathrm{C}_{\text {in }} / \mathrm{C}_{\text {out }} \cdot 1 / \theta \cdot \mathrm{V}_{\mathrm{M}} / \mathrm{V}_{\mathrm{E}}
$$

$\mathrm{C}_{\mathrm{in}} \quad=$ konsentrasi materi di dalam fasa internal stelah pemisahan

$\mathrm{C}_{\text {out }} \quad=$ konsentrasi materi di dalam fasa eksternal setelah pemisahan

$\theta \quad=$ waktu kontak fasa emulsi dengan fasa eksternal

Hubungan antara koefisien distribusi D dengan prosen ekstraksi \% E adalah sebagai berikut

$$
D=\frac{\% E}{(100-\% E)} \text { atau } \% E=\frac{100 . D}{(D+1)}
$$

Faktor pemisahan antara kation ( $\beta$ ) untuk memisahkan dua jenis ion logam misalnya $\mathrm{M}^{\mathrm{n}+}$ dan $\mathrm{N}^{\mathrm{n}+}$ merupakan perbandingan nilai antara angka banding distribusi senyawa 1 terhadap nilai angka banding distribusi senyawa 2 ditulis sebagai berikut:

$$
\beta=\frac{D_{M n+}}{D_{\mathrm{Nn}^{+}}}
$$

Besarnya harga faktor pemisahan ( $\beta$ ) menentukan apakah ion $\mathrm{M}^{\mathrm{n}+}$ dan ion $\mathrm{N}^{\mathrm{n}+}$ dapat dipisahkan dengan baik. Untuk mendapatkan ion $\mathrm{M}^{\mathrm{n}+}$ sebanyak $99 \%$ dan menyisakan hanya $1 \%$ ion $\mathrm{N}^{\mathrm{n}+}$ dalam fasa eksternal dibutuhkan nilai $(\beta)$ sebesar sekitar $10^{4}$.

Prinsip ekstraksi membran cair didasarkan pada distribusi zat terlarut dalam tiga pelarut yang saling terpisah yaitu pada fasa air eksternal(FAE), fasa membran(FM) dan fasa air internal (FAI). Mula-mula dipandang suatu ekstraksi membran cair hanya terdapat dua fasa membran (yang didalamnya memuat fasa air internal sebagai fasa terdispersi). Menurut hukum distribusi Nerst : jika $\left[\mathrm{X}_{1}\right]$ adalah konsentrasi zat terlarut dalam fasa 1 dan $\left[\mathrm{X}_{2}\right]$ fasa adalah konsentrasi zat terlarut dalam fasa 2 , maka pada keseimbangan didapat :

$$
\text { Konstanta distribusi }(\mathrm{Kd})=\frac{\left[\mathrm{X}_{1}\right]}{\left.--\mathrm{X}_{2}\right]}
$$

Konstanta distribusi ini tidak tergantung pada konsentrasi total zat terlarut pada kedua fasa tersebut. Konsentrasi distribusi hanya berlaku untuk species tunggal dan tidak melibatkan reaksi samping seperti asosiasi, dissosiasi atau polimerisasi. Sehingga dalam keadaan ideal tersebut harga $\mathrm{Kd}$ sama dengan $\mathrm{D}$ yang disebut koefisien distribusi yaitu perbandingan konsentrasi total zat terlarut dalam kedua pelarut. Dalam suatu proses ekstraksi membran cair maka terdapat distribusi zat terlarut dalam tiga fasa. Ada dua harga konstanta distribusi 
yaitu konstanta distribusi ekstraksi $\left(\mathrm{Kd}_{\text {eks }}\right)$ dan konstanta distribusi re-ekstraksi $\left(\mathrm{Kd}_{\text {strip }}\right) \cdot \mathrm{Kd}_{\text {eks }}$ adalah konstanta distribusi ekstraksi, merupakan perbandingan konsentrasi zat terlarut $\mathrm{M}$ pada fasa membran dengan fasa air eksternal.

$$
\mathrm{Kd}_{\text {eks }}=\frac{[\mathrm{M}]_{\text {membran }}}{[\mathrm{M}]_{\text {air ekstemal }}}
$$

Efisiensi ekstraksi $\left(\mathrm{E}_{\text {eks }}\right)$ ion logam dengan teknik emulsi membran cair pada penelitian ini, dapat dinyatakan dengan rumus sebagai berikut :

$$
\text { Efisiensi ekstraksi }\left(\mathrm{E}_{\text {eks }}\right)=\frac{\mathrm{Kd}_{\text {eks }}}{\mathrm{Kd}_{\text {eks }}+1} \times 100 \%
$$

Penelitian ini merupakan penelitian pendahuluan untuk mengolah limbah industri penyamakan kulit yang mengandung krom.

\section{BAHAN DAN METODA PENELITIAN}

\section{Peralatan dan Bahan}

1.1. Alat-alat yang digunakan : Satu set alat pengaduk mekanik "Ultra-Turrax T-50" dari Janke and Kunkel Ika-Laboratecknek, magnet stirrer, batang pengaduk, $\mathrm{pH}$ meter, neraca analitik, wadah pembuat emulsi, tabung, corong pisah, stopwatch serta alatalat gelas.

1.2. Bahan-bahan yang digunakan : Krom nitrat, asam nitrat, tri octyl amin (TOA), asam sulfat, $\mathrm{Na} \mathrm{OH}$ aquadest, sorbitan monooleat (SPAN-80), minyak tanah (kerosen ), es, butanol, feri nitrat, seng nitrat

\section{Cara Penelitian}

2.1. Mencari kondisi optimum membran cair : prosen surfaktan, 1, 2, 3, 4, 5 dan $6 \%$, kecepatan pengadukan $2000,4000,6000,8000$ dan 10000 rpm serta lama pembuatan membran 2,4,6, 8, 10, 12 dan 15 menit campuran diaduk dengan pengaduk mekanik "Ultra-Turrax T-50", kemudian dilihat pengaruh \% surfaktan, kecepatan pengadukan dan waktu terhadap kestabilan membran.

2.2. Pembuatan membran cair: dari kondisi optimum diatas prosen surfaktan dengan fasa internal natrium hidroksida. Fasa organik adalah tri octyl amin dalam kerosen volume total membran sebanyak $100 \mathrm{ml}$. Kemudian dilakukan kecepatan dan waktu pembuatan membran yang optimum dari cara kerja 1., selanjutnya digunakan pemisahan krom dalam limbah untuk mengetahui larutan umpan dengan lama pengadukan $(0,5,10,15,20,25$ dan 30 menit), dibandingkan dengan sistem ekstraksi cair-cair. 


\section{HASIL DAN PEMBAHASAN}

\section{Tabel 1.Pengaruh fasa air dan minyak dalam menentukan surfaktan yang optimum. dan kestabilan}

\begin{tabular}{|l|c|c|c|c|c|c|}
\cline { 2 - 7 } \multicolumn{1}{c|}{} & \multicolumn{4}{c|}{ Volume (ml) } & \multicolumn{2}{c|}{ Kestablian } \\
\hline $\begin{array}{l}\text { Persen } \\
\%\end{array}$ & $\begin{array}{c}\text { Fasa } \\
\text { Eksternal } \\
\text { Surfaktan }\end{array}$ & $\begin{array}{c}\text { Fasa } \\
\text { Membran } \\
(\text { FM) }\end{array}$ & $\begin{array}{c}\text { Air ter- } \\
\text { ekstrak }\end{array}$ & $\begin{array}{c}\text { Membran } \\
\text { ter ekstrak }\end{array}$ & $\begin{array}{c}\text { Tanpa } \\
\text { Pemanas- } \\
\text { an }\end{array}$ & $\begin{array}{c}\text { Dengan } \\
\text { Pemanas- } \\
\text { an }\end{array}$ \\
\hline 1 & 23,00 & 17,00 & - & 3,00 & 2 hari & 4 menit \\
2 & 21,90 & 18,10 & - & 1,90 & 3 hari & 6 menit \\
3 & 21,00 & 19,00 & - & 1,00 & 8 hari & 13 menit \\
4 & 20,10 & 19,90 & - & 0,10 & 11 hari & 10 menit \\
5 & 20,30 & 19,70 & - & 0,30 & 10 hari & 12 menit \\
6 & 19,90 & 20,10 & 0,10 & - & 9 hari & 16 menit \\
\hline
\end{tabular}

Pada tabel 1. menunjukkan bahwa konsentrasi surfaktan $4 \%$, merupakan konsentrasi optimum yang menghasilkan emulsi yang paling stabil. Pada kondisi itu praktis tidak ada air yang terekstrak ke membran dan demikian pula tidak ada membran terekstrak ke fasa eksternal. Data ini dibuat dengan pengamatan kestabilan emulsi mencapai 11 hari tanpa pemanasan dan mencapai 10 menit dengan pemanasan. Pada konsentrasi surfaktan kurang dari $4 \%$ sebenarnya tidak ditemukan air terekstrak, namun membran terekstrak semakin banyak dengan berkurangnya konsentrasi surfaktan. Surfaktan dapat berfungsi sebagai penyestabil emulsi karena dapat menurunkan tegangan permukaan dan menentukan kekuatan mekanik film antar muka. Dengan semakin meningkatnya konsentrasi surfaktan dalam fasa membran maka tegangan permukaan juga akan turun. Akan tetapi bila konsentrasi surfaktan terlalu banyak dalam fasa membran dapat menyebabkan meningkatnya viskositas membran.

Tabel 2 menunjukkan pengaruh waktu pengadukan terhadap kestabilan membran. Pada pengadukan 6 menit, diperoleh kestabilan emulsi yang tinggi yakni emulsi dapat bertahan hingga 9 hari bila dibiarkan pada temperatur kamar. Kestabilan ini dapat dibuktikan pula dengan volume fasa membran yang tidak berubah baik tanpa pemanasan maupun dengan pemanasan. Pengadukan kurang dari 6 menit belum cukup membentuk emulsi yang stabil. Pengadukan yang lebih dari 6 menit menyebabkan penurunan kembali kestabilan emulsi walaupun volume fasa membran terus meningkat. Diduga semakin lama pengadukan dilakukan, temperatur sistem menjadi meningkat sehingga volume terekstraksi menjadi meningkat dan menyebabkan butiran menjadi mudah pecah. 
Tabel 2.Pengaruh waktu pengadukan terhadap kestabilan membran

\begin{tabular}{|c|c|c|c|c|}
\cline { 2 - 5 } \multicolumn{1}{c|}{} & \multicolumn{2}{c|}{ Kestabilan Membran } & \multicolumn{2}{c|}{ Volume Fasa Membran (ml) } \\
\hline $\begin{array}{c}\text { Waktu } \\
\text { Pengadukan } \\
\text { (menit) }\end{array}$ & $\begin{array}{c}\text { Tanpa } \\
\text { Pemanasan }\end{array}$ & $\begin{array}{c}\text { Dengan } \\
\text { Pemanasan }\end{array}$ & $\begin{array}{c}\text { Tanpa } \\
\text { Pemanasan }\end{array}$ & $\begin{array}{c}\text { Dengan } \\
\text { Pemanasan }\end{array}$ \\
\hline 2 & 3 hari & 13 menit & 19,50 & 20,50 \\
4 & 6 hari & 11 menit & 19,80 & 20,20 \\
6 & 9 hari & 10 menit & 20,00 & 20,00 \\
8 & 8 hari & 12 menit & 21,20 & 18,80 \\
10 & 7 hari & 12 menit & 21,40 & 18,60 \\
15 & 4 hari & 15 menit & 22,20 & 17,80 \\
\hline
\end{tabular}

Tabel 3. Pengaruh kecepatan pengadukan pembentukan membran terhadap kestabilan.

\begin{tabular}{|c|c|c|c|c|}
\cline { 2 - 5 } \multicolumn{1}{c|}{} & \multicolumn{2}{c|}{ Kestabilan Membran } & \multicolumn{2}{c|}{ Volume Fasa Membran (ml) } \\
\hline $\begin{array}{c}\text { Kecepatan } \\
\text { Pengadukan } \\
(\mathrm{rpm})\end{array}$ & $\begin{array}{c}\text { Tanpa } \\
\text { Pemanasan }\end{array}$ & $\begin{array}{c}\text { Dengan } \\
\text { Pemanasan }\end{array}$ & $\begin{array}{c}\text { Tanpa } \\
\text { Pemanasan }\end{array}$ & $\begin{array}{c}\text { Dengan } \\
\text { Pemanasan }\end{array}$ \\
\hline 2000 & 3 hari & 15 menit & 19,00 & 21,00 \\
4000 & 7 hari & 13 menit & 19,60 & 20,40 \\
6000 & 9 hari & 12 menit & 19,80 & 20,80 \\
8000 & 10 hari & 10 menit & 20,10 & 19,90 \\
10000 & 9 hari & 14 menit & 20,80 & 19,20 \\
\hline
\end{tabular}

Tabel 3 memperlihatkan pengaruh intensitas pengadukan terhadap kestabilan membran. Pengadukan campuran fasa organik dengan fasa air dimaksudkan untuk mempercepat dispersi emulsi. SPAN-80 berperan sebagai emulgator, yang dalam hal ini menurunkan tegangan antar muka fasa air dengan fasa minyak/kerosen. Pengadukan dengan kecepatan antara $8000 \mathrm{rpm}$ menghasilkan emulsi yang paling stabil yakni hingga 10 hari pada temperatur kamar. Kecepatan pengadukan yang lebih besar dari $8000 \mathrm{rpm}$ kembali menurunkan kestabilan, karena semakin memungkinkan terbentuknya creaming. Keadaan ini diperkuat dengan semakin meningkatnya volume air dalam fasa eksternal setelah proses ekstraksi. 
Tabel 4. Data \% surfaktan terhadap waktu awal flokulasi dan vol fasa internal/vol fasa internal semula( $(\Gamma)$

\begin{tabular}{|l|c|c|c|c|c|c|c|c|c|c|}
\cline { 2 - 10 } \multicolumn{1}{c|}{} & \multicolumn{10}{c|}{ Waktu Awal Flokulasi (jam) } \\
\hline $\begin{array}{l}\text { Sur- } \\
\text { faktan }\end{array}$ & $\begin{array}{c}2000 \\
\mathrm{rpm}\end{array}$ & $\Gamma$ & $\begin{array}{c}4000 \\
\mathrm{rpm}\end{array}$ & $\Gamma$ & $\begin{array}{c}6000 \\
\mathrm{rpm}\end{array}$ & $\Gamma$ & $\begin{array}{c}8000 \\
\mathrm{rpm}\end{array}$ & $\Gamma$ & $\begin{array}{c}10000 \\
\mathrm{rpm}\end{array}$ & $\Gamma$ \\
\hline 1 & 12 & 1 & 16 & 1 & 48 & 0,90 & 48 & 0,90 & 48 & 1 \\
2 & 44 & 0,90 & 72 & 0,90 & 144 & 0,80 & 164 & 0,60 & 158 & 0,80 \\
3 & 92 & 0,60 & 144 & 0,60 & 196 & 0,40 & 216 & 0,10 & 204 & 0,12 \\
4 & 196 & 0,20 & 204 & 0,20 & 216 & 0,08 & 240 & 0,04 & 216 & 0,08 \\
5 & 166 & 0,50 & 204 & 0,30 & 208 & 0,10 & 240 & 0,08 & 216 & 0,08 \\
6 & 166 & 0,60 & 196 & 0,30 & 208 & 0,18 & 228 & 0,12 & 192 & 0,12 \\
\hline
\end{tabular}

Bila SPAN-80 yang ditambahkan pada fasa organik kurang, maka tidak dapat menghasilkan membran cair yang stabil. Dari tabel 4 terlihat harga $\tau$-nya, pada penambahan SPAN-80 kurang, maka butir-butir terdispersi tidak stabil, sehingga mudah flokulasi. Akibatnya dengan penambahan fasa eksternal, fasa membran dan fasa internal akan bercampur. Tetapi jika surfaktan yang cenderung lipofil terlalu banyak, kemungkinan dapat terjadi emulsi membran bentuk lain. Hasil penelitian memperlihatkan bahwa SPAN-80 yang diperlukan untuk pembentukan membran antara $4-5 \%$ terhadap volume fasa organik. Pengaruh kecepatan putar saat pembentukan membran terhadap waktu awal flokulasi tidak terlalu signifikan, demikian pula pengaruh kecepatan terhadap harga $\tau$ dalam tabel menunjukkan bahwa pada penambahan SPAN- $804 \%$ ada perbedaan waktu awal flokulasi yang cukup besar. Hal ini menunjukkan bahwa pemakaian SPAN-80 lebih kecil dari $4 \%$ ternyata masih kurang stabil. Diatas $4 \%$ juga akan mengalami penurunan waktu awal flokulasi

Pengaruh konsentrasi TOA dalam fasa membran terhadap efisiensi prosen ekstraksi cair-cair, prosen ekstraksi dengan ekstraksi membran-cair disajikan pada Tabel 5.

Tabel 5. Pengaruh ekstraktan TOA terhadap prosen ekstraksi cair-cair serta prosen efisiensi ekstraksi dengan membran-cair.

\begin{tabular}{|c|c|c|}
\cline { 2 - 3 } \multicolumn{1}{c|}{} & \multicolumn{2}{c|}{ Prosen } \\
\hline Konsentrasi TOA (v/v\%) & Ekstraksi Cair-Cair & Ekstraksi Membran-Cair \\
\hline 1 & 61,54 & 88,65 \\
2 & 71,40 & 91,80 \\
3 & 79,15 & 95,67 \\
4 & 83,85 & 91,19 \\
5 & 87,10 & 89,19 \\
6 & 87,00 & 87,90 \\
\hline
\end{tabular}

$$
\mathrm{Cr}_{2} \mathrm{O}_{7}\left(\mathrm{NO}_{3}\right)_{2(\mathrm{w})}+2 \mathrm{TOA}_{(0)} \Leftrightarrow \mathrm{Cr}_{2} \mathrm{O}_{7}\left(\mathrm{NO}_{3}\right)_{2} \cdot 2 \mathrm{TOA}_{(0)}
$$

Krom ter-ekstrak dalam bentuk $\mathrm{Cr}_{2} \mathrm{O}_{7}\left(\mathrm{NO}_{3}\right)_{2}$ oleh TOA sehingga dengan meningkatnya $\mathrm{Cr}_{2} \mathrm{O}_{7}\left(\mathrm{NO}_{3}\right)_{2}$ dalam larutan, koefisien distribusi krom akan meningkat dan efisiensi ekstraksi akan meningkat pula. 
Penambahan TOA pada fasa membran mempengaruhi kestabilan membran cair yang terbentuk karena TOA merupakan salah satu komponen pembentuk membran. Pada tabel 5. terlihat efisiensi ekstraksi mencapai kondisi optimum pada penggunaan TOA sebesar 3\%, sedangkan untuk ekstraksi cair-cair kondisi 3\% belum optimum. Semakin besar konsentrasi TOA semakin turun prosen efisiensi dalam ekstraksi membran cair, tetapi untuk ekstraksi caircair semakin tinggi konsentrasi hasil makin naik. Konsentrasi TOA dibawah harga optimum menyebabkan TOA tidak cukup mampu untuk mengkomplekkan semua ion logam yang ada dalam larutan sehingga anion-anion yang ada dalam air ikut serta berperan dalam pembentukan kompleks logam-zat pembawa dan kestabilan komplek yang dihasilkan sangat ditentukan oleh jenis anion dalam larutan. Penggunaan konsentrasi TOA diatas harga optimum akan mempengaruhi hasil ekstraksi, karena TOA sebagai senyawa zat pembawa dalam hal ini bersifat penggerak di dalam membran setelah lepas ion logam pada fasa internal, senyawa zat pembawa ini akan segera berdifusi balik ke fasa eksternal untuk mengkomplekkan ion logam kembali. Pemakaian zat pembawa terlalu besar memungkinkan terjadinya interaksi gugus polar zat pembawa dengan molekul air dalam fasa eksternal sehingga terjadi proses osmosa. Selain itu dengan penambahan konsentrasi natrium hidroksida pada fasa internal untuk memperoleh membran yang stabil. Dengan konsentrasi natrium hidroksida $1 \% \mathrm{v} / \mathrm{v}$ hanya dapat diperoleh membran cair yang stabil pada pemakaian TOA $3 \%$. Jadi penambahan ekstraktan pada fasa membran adalah terbatas karena kendala pada kestabilan membran yang terjadi.

Lamanya waktu kontak antara fasa membran dengan fasa eksternal dapat mempengaruhi perolehan prosen ekstraksi, karena selama ekstraksi tersebut membran yang terbentuk dapat mengalami pemecahan akibat pengadukan ataupun proses difusi belum sempurna apabila dilakukan dalam waktu yang singkat. Dari tabel 6. terlihat bahwa waktu kontak yang optimum terjadi menit ke 15 , sedangkan sebelum menit ke 15 , prosen ekstraksi lebih sedikit. Hal ini terjadi karena pada awal kontak tersebut pembentukan butir-butir membran belum seragam dan merata didalam fasa eksternal. Dengan demikian hanya sedikit ion-ion krom yang berdifusi ke dalam butir-butir membran.

Pada saat waktu kontak telah melewati kondisi optimum (>15 menit), terjadi penurunan prosen ekstraksi ion krom. Hal ini terjadi karena pada saat tersebut sebagian membran mengalami pemecahan karena pengaruh pengadukan, sehingga ion-ion logam yang telah terperangkap ke dalam butir-butir membran lepas kembali ke fasa eksternal

Tabel 6. Pengaruh waktu kontak antara fasa membran dan fasa eksternal/umpan terhadap prosen ekstraksi

\begin{tabular}{|c|c|c|}
\cline { 2 - 3 } \multicolumn{1}{c|}{} & \multicolumn{2}{c|}{ Prosen Efisiensi (\%) } \\
\hline Lama Ekstrasi (menit) & Ekstraksi Membran-Cair & Ekstraksi Cair-Cair \\
\hline 2.5 & 80,50 & 72,55 \\
5 & 84,50 & 75,90 \\
7.5 & 89,10 & 85,70 \\
10 & 92,40 & 86,66 \\
15 & 97,80 & 81,24 \\
20 & 87,00 & 76,45 \\
25 & 78,00 & 75,50 \\
30 & 73,00 & 73,90 \\
\hline \multicolumn{2}{|c}{} \\
\hline \multicolumn{3}{|c}{} \\
\hline \multicolumn{3}{|c|}{ Majalah Barang Kulit, Karet dan Plastik, Vol. XV, No. 2, Tahun 1999 } \\
\hline
\end{tabular}


Pengaruh dari lamanya waktu kontak terhadap harga D' dapat dilihat dari persamaan 3. Dari persamaan 3 tersebut terlihat bahwa dengan meningkatnya waktu kontak maka harga D' semakin kecil karena pecahnya emulsi, sehingga harga prosen ekstraksi juga menjadi berkurang.

Untuk mengetahui selektivitas pemisahan krom dengan membran cair terhadap ionion ferro dan ion-ion seng, maka dilakukan percobaan dengan mencampurkan ketiga jenis ion tersebut dalam fasa eksternal dengan konsentrasi yang sama. Pemilihan kedua jenis itu didasarkan atas kemampuan ion-ion tersebut bereaksi dengan ion nitrat membentuk senyawa komplek sebagaimana ion krom

Dari Tabel 7. terlihat bahwa kondisi optimum ekstraksi terjadi pada menit ke 15 . Pada menit ke 15 tersebut krom terekstraksi sebanyak 92,20\%, ion Fe terekstraksi sebanyak 5,50\% dan ion $\mathrm{Zn}$ terekstraksi sebanyak $0,10 \%$. data percobaan yang lain dapat dilihat dalam tabel 7. Berdasarkan persamaan (4) dan (5) berikut ini dapat dihitung faktor pemisahan (b) ketiga ion tersebut.

Tabel 7. Selektifitas pemisahan krom terhadap Fe dan $\mathrm{Zn}$ dengan membran cair \% Ekstraksi Campuran

\begin{tabular}{|c|c|c|c|c|}
\cline { 3 - 4 } \multicolumn{2}{c|}{} & \multicolumn{3}{c|}{ \% Ekstraksi Campuran } \\
\hline Waktu Ekstraksi (menit) & \multicolumn{2}{c|}{ \% Ekstraksi Cr } & \% Ekstraksi Fe & \% Ekstraksi Zn \\
\hline 5 & 88,10 & 89,20 & 6,90 & 1,45 \\
10 & 95,70 & 90,60 & 3,15 & 1,30 \\
15 & 98,40 & 92,20 & 4,35 & 0,10 \\
20 & 89,60 & 84,90 & 4,85 & 0,20 \\
25 & 87,80 & 84,50 & 4,00 & 0,25 \\
30 & 88,30 & 82,30 & 4,05 & 0,20 \\
\hline
\end{tabular}

Berdasarkan perhitungan diperoleh faktor pemisahan $(\beta) \mathrm{Cr} / \mathrm{Fe}=261,7$ dan faktor pemisahan $(\beta) \mathrm{Cr} / \mathrm{Zn}=13085$, dan faktor pemisahan $(\beta) \mathrm{Fe} / \mathrm{Zn}=50$. Dari hasil perhitungan ini dapat disimpulkan bahwa $\mathrm{Cr}$ dapat dipisahkan cukup baik, sedangkan lainnya kurang baik dipisahkan dengan kondisi diatas, artinya bahwa selektifitas membran cair adalah ada yang tinggi dan rendah. Ekstraksi yang baik diperoleh apabila harga faktor pemisahan $(\beta)$ sekitar $10^{4}$, dimana pada keadaan ini $99 \%$ ion utama dapat dipisahkan, sementara ion pengganggu yang ikut terekstraksi hanya $1 \%$.

\section{KESIMPULAN}

Berdasarkan hasil penelitian yang telah dilakukan dapat diambil beberapa kesimpulan yaitu:

1. Teknologi membran cair dapat digunakan untuk ekstraksi ion krom dalam larutan.

2. Kondisi optimum yang diperoleh untuk mengekstraksi krom dari larutan umpan hingga memperoleh effisiensi $97,80 \%$ adalah konsentrasi asam nitrat dalam fasa eksternal $3 \mathrm{M}$, konsentrasi tri oktil amin (TOA) dalam fasa membran 5\% (v/v), konsentrasi natrium hidroksida dalam fasa internal $1 \%(\mathrm{v} / \mathrm{v})$ adalah $1 \mathrm{M}$, dan lamanya waktu ekstraksi 15 menit, serta perbandingan volume fasa membran dan volume fasa eksternal adalah 1:3. 
3. Kestabilan emulsi membran dipengaruhi oleh prosen surfaktan sebagai penstabil, waktu dan intensitas kecepatan pengadukan terhadap waktu awal flokulasi/pecahnya emulsi.

4. Berdasarkan hasil pengamatan pembuatan membran-cair emulsi yang menggunakan Span80 sebagai surfaktan, kerosen sebagai pelarut, emulsi stabil diperoleh bila pembuatan di lakukan pada perbandingan volume fasa organik dan fasa internal sebesar $1: 1$, konsentrasi surfaktan sebesar 4-\% (v/v) dengan intensitas pengadukan $8000 \mathrm{rpm}$ selama 6 menit

5. Bila dibandingkan dengan cara ekstraksi pelarut, maka peningkatan dalam fasa umpan pada cara ekstraksi membran memperlihatkan harga yang lebih besar.

6. Adanya kation Fe dan $\mathrm{Zn}$ dalam fasa eksternal menurunkan prosen ekstraksi.

\section{DAFTAR PUSTAKA}

Abou-Nemeh and Van Pethegem, 1993. Membrane Recycling in the Liquid Surfactant Membrane Process. Ind. Eng. Chem. Res., 32, 143-147.

Anief, M., 1985. Emulsi. Fakultas Farmasi Universitas Gadjah Mada, Yogyakarta.

Frankenfeld, J.W., Chan, R.P., Li., N.N., 1981. Extraction of Copper by Liquid Membranes. Sep. Sci. Tech., 16, 4, 385 - 402.

Hayworth, H.C., Burns, W.A., 1993. Extraction Of Uranium From Wet Phosphoric Acid By Liquid membrane. Sep. Sci. Technol., 18, 493 - 521.

Johanes, H., 1973. Pengantar Kimia Koloid dan Kimia Permukaan Universitas Gadjah Mada Press, Yogyakarta.

Li, N.N., 1971. Permeation Through Liquid Surfactant Membranes. AICHE Journal, 17.

Li, N.N., 1971. Separation of Hydrocarbon by Liquid Membranes. Ind. Eng. Che. Process Develop., 10, 315 - 321. 